\title{
From the Editor-in-Chief
}

\author{
Kimon P. Valavanis
}

Published online: 25 May 2011

(C) Springer Science+Business Media B.V. 2011

\section{Dear Colleagues:}

As we approach the end of 2011, we are making every effort to complete reviews make final decisions for as many papers as possible. Our journal has improved considerably over the years, and it is now recognized as one of the major ones in the field of Robotics and Automation. This has resulted in receiving more papers per year, thus, the review process is more demanding. As always, we aim at publishing the highest quality papers, but we also recognize the importance of making timely decisions. It is my pleasure to inform you that effective January 12012 , each issue will have more pages. In this way, we will be able to publish more papers per issue. This action is the least we could make honoring the trust and support of our authors and readers. We are looking forward to better days.

Enjoy the issue.

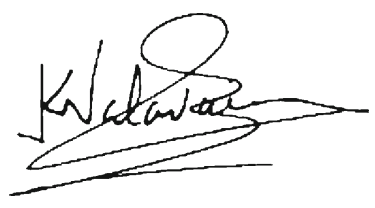

Kimon P. Valavanis

Editor-in-Chief

K. P. Valavanis $(\bowtie)$

Journal of Intelligent and Robotic Systems,

Department of Electrical and Computer Engineering,

School of Engineering and Computer Science,

University of Denver, Denver, CO, 80208, USA

e-mail: kvalavan@du.edu 